hydrogen. Both sets of data are plotted in Fig. 1, along with the Vegard's law lines based on the accepted values for the pure metals as listed in [78Bea, 78Kos]. All of the data as plotted have been adjusted by a small increment so that the spacings for the pure metals would agree with the accepted lattice spacing values. The Ce-rich alloys show a positive deviation from the Vegard's law approximation. The Lu-rich alloy had a large negative deviation in the $c$ spacing, but was close to ideality in the $a$ spacing.

\section{Cited References}

62Gsc: Gschneidner, K. A., Jr., Elliott, R. O., and Prince, M. Y., in Rare Earth Research, Nachman, J. F. and Lundin, C. E., Ed., Gordon and Breach Science Publishers, New York, 71 (1962). 69Har: Harris, I. R. and Raynor, G. V., J. Less-Common Met., 17, 336 (1969).

78Bea: Beaudry, B.J. and Gschneidner, K. A., Jr., in Handbook on the Physics and Chemistry of Rare Earths, Vol. 1-Metals, Gschneidner, K.A., Jr. and Eyring, L., Ed., North-Holland Publishing Co., Amsterdam, 215 (1978).

78Kos: Koskenmaki, D. C. and Gschneidner, K. A., Jr., in Handbook on the Physics and Chemistry of Rare Earths, Vol. 1Metals, Gschneidner, K.A., Jr. and Eyring, L., Ed., NorthHolland Publishing Co., Amsterdam, 337 (1978).

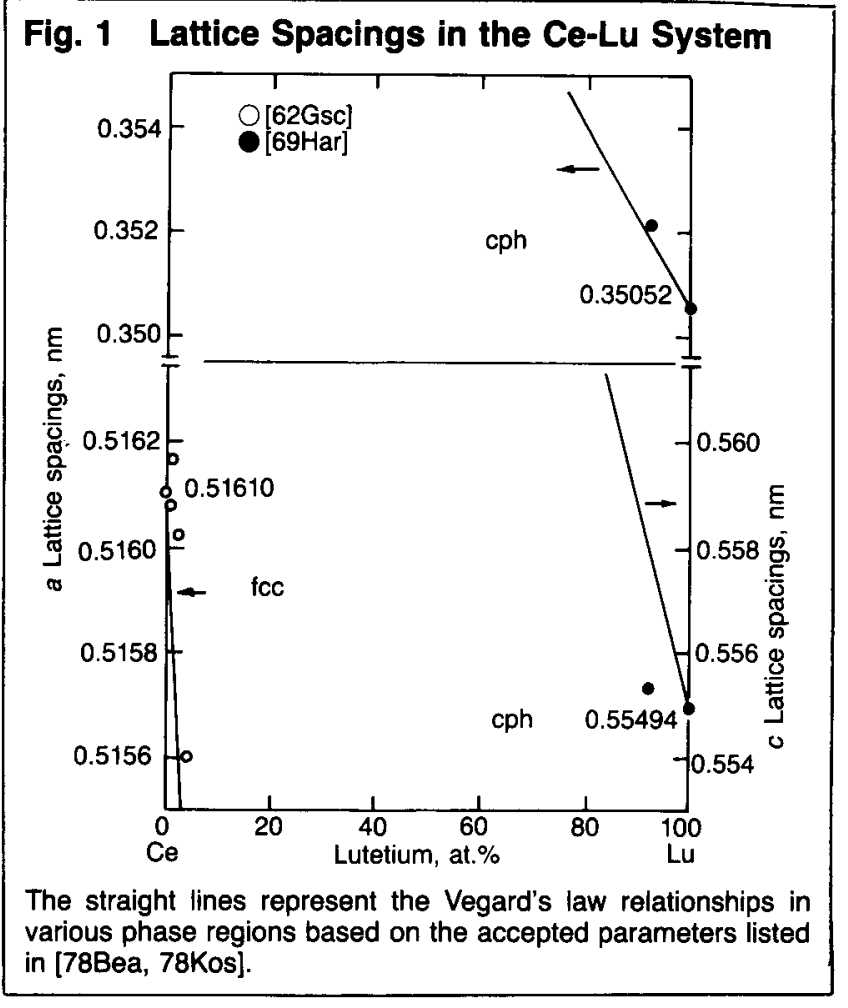

Ce-Lu evaluation contributed by K. A. Gschneidner, Jr., Director, and F. W. Calderwood, Rare-earth Information Center, Ames Laboratory, Iowa State University, Ames, Iowa 50011. This work was supported by the Department of Energy through the Joint Program on Critical Compilation of Physical and Chemical Data coordinated through the Office of Standard Reference Data, National Bureau of Standards. Additional support was contributed by: Th. Goldschmidt AG, Essen, West Germany; Molycorp, Inc., Union Oil Co. of California, Los Angeles, CA; Reactive Metals \& Alloys Corp., West Pittsburg, PA; Ronson Metals Corp., Newark, NJ; and Santoku Metal Industry Co. Ltd., Kobe, Japan. Literature searched through 1981. Professor Gschneidner is the ASM/NBS Data Program Category Editor for binary rare-earth alloys.

\title{
The Ce-Yb (Cerium-Ytterbium) System
}

140.12

173.04

\author{
By K. A. Gschneidner, Jr. and F.W. Calderwood \\ lowa State University
}

\section{Phase Relationships}

Spedding and Daane [61Spe] reported that a $50 \%$ alloy of $\mathrm{Yb}$ in Ce was observed to contain two immiscible liquids. An X-ray study of these phases indicated a solubility of about $1 \% \mathrm{Ce}$ in $\mathrm{Yb}$ and about $3 \% \mathrm{Yb}$ in Ce. King [69Kin] studied electrical resistance at the $\mathrm{Yb}$-rich end of the $\mathrm{Ce}-\mathrm{Yb}$ phase diagram and observed that an addition of 10 at.\% Ce moved the resistance peak in pure $\mathrm{Yb}$ from $39.37 \mathrm{kB}$ to $\sim 52.7 \mathrm{kB}$ at room temperature.

\section{Cited References}

61Spe: Spedding, F.H. and Daane, A.H., in IS-350, Annual Summary Research Report in Chemistry, July 1, 1960-June 30, 1961, Ames Laboratory at Iowa State University, Ames, IA, 27 (1961).

69Kin: King, E., AERE-R5954, Atomic Energy Research Establishment, Harwell, Bks. (1969).

Ce-Yb evaluation contributed by K.A. Gschneidner, Jr., Director, and F.W. Calderwood, Rare-earth Information Center, Ames Laboratory, Iowa State University, Ames, Iowa 50011. This work was supported by the Department of Energy through the Joint Program on Critical Compilation of Physical and Chemical Data coordinated through the Office of Standard Reference Data, National Bureau of Standards. Additional support was contributed by: Th. Goldschmidt AG, Essen, West Germany; Molycorp, Inc., Union Oil Co. of California, Los Angeles, CA; Reactive Metals \& Alloys Corp., West Pittsburg, PA; Ronson Metals Corp., Newark, NJ; and Santoku Metal Industry Co. Ltd., Kobe, Japan. Literature searched through 1981. Professor Gschneidner is the ASM/NBS Data Program Category Editor for binary rare-earth alloys. 